DOI https://doi.org/10.18551/rjoas.2018-12.30

\title{
TECHNICAL EFFICIENCY OF TIDAL RICE FARMING IN SOUTH KALIMANTAN, INDONESIA: STOCHASTIC FRONTIER ANALYSIS APPROACH
}

\author{
Azis $Y$ * $^{*}$ \\ Agricultural Economics and Social Sciences Department, Faculty of Agriculture, \\ Lambung Mangkurat University, Banjarbaru, Indonesia \\ Hanani N., Syafrial, Muhaimin A.W. \\ Agricultural Economics and Social Sciences Department, Faculty of Agriculture, \\ University of Brawijaya, Malang, Indonesia \\ *E-mail: yusuf azis@ulm.ac.id
}

\begin{abstract}
Development of tidal land for rice cultivation continues in South Kalimantan, but there are obstacles that must be faced, namely one of which is the low productivity caused by technical efficiency of input use. Technical efficiency is the ability of farms to produce maximum output by using a specific input. This research objecyives were to analyze the factors affecting tidal rice production, analyze the technical efficiency of tidal paddy farming using Stochastic Frontier Analysis (SFA) approach and analyze the determinant factors affecting technical inefficiency tidal wetland rice farming. Data collected from interviews with 50 farmers of paddy and analyzed with Frontier 4.1 software to answer the first and second objectives, as well as all the parameters for efficiency levels estimated by maximum likelihood method (MLE) using Stata program ver. 11 to answer the third goal.The results showed that production of paddy farm influenced significantly by factors of area planted, inorganic fertilizers and pesticides. The average technical efficiency is already high at 0.9996 , approaching 1.0000 as technical efficiency index expected. The inability of farmers in achieving maximum production solely due to managerial farmers' factor of 0.01 percent, while 99.99 percent are caused by other factors. The deciding factor affecting technical inefficiency of rice farming is the number of household members and the frequency of extension.
\end{abstract}

\section{KEY WORDS}

Technical efficiency, paddy farm, tidal rice fields, stochastic frontier analysis.

Tidal land belonging marsh area that is affected by the huge tidal overflow and doubles pairs from rivers or the sea, either directly or indirectly. These lands belong to the wetland ecosystem with the potential to be developed into agricultural land. The land that has been used as rice fields in Kalimantan until 2006 covering an area of 333,601 ha (H.Subagio et al., 2015). South Kalimantan had 178,908 ha of tidal rice fields that have been cultivated, the highest for the region of Borneo, where most of the 102,361 ha, or an area in Barito Kuala (Department of Agriculture TPH South Kalimantan, 2016).

Utilization of tidal land in the form of marginal lands for paddy is not easy. It should be understood that the typical properties of tidal land. Failure understanding of the tidal land characteristics can make rice field development will be faced with many problems.

Rice productivity is still relatively low becomes a problem on tidal land. Low productivity is allegedly closely associated with the issue of efficient use of inputs. Allocation of input use also allegedly still not optimal (Kurniawan, AY 2010).

One indicator of efficiency is that if a certain number of outputs can be generated using a combination of fewer inputs. The efficiency will reduce production costs. The minimum cost of production which will make output more competitive prices and will ultimately improve the competitiveness (Kurniawan, AY 2010). 
This research aimed to analyze the factors affecting tidal rice production, analyze the technical efficiency of tidal rice farming using Stochastic Frontier Analysis (SFA) approach and analyze the determinant factors affecting technical inefficiency on tidal rice farming.

\section{METHODS OF RESEARCH}

Determination of Research Areas and Farmers Sample. This study was conducted in South Kalimantan province, which is a center of tidal rice production, and a granary in Indonesia. However, productivity of paddy fields are still far below the average of national productivity.

The sampling method used was multistage cluster sampling. In the first stage sampling was selected one district with the most extensive tidal rice cultivation, which was Barito Kuala (Batola) District.

In the second stage, the election of a sub-district sample that had the largest area of tidal rice production in Batola District, which was the Tabunganen Sub-District. Followed by a third phase, namely the selection of the sample village that became a production center, which was the Village of Tabunganen Pemurus. In the fourth stage of the election of a simple random sample of farmers, which was taken $10 \%$ of the total population of tidal land rice farmers in the sample village, as many as 50 respondents out of 495 rice farmers in the village of Tabunganen Pemurus.

Data Analysis Method. Research carried out a micro analysis that focuses on the theoretical and empirical study of the real condition of the tidal rice farming in South Kalimantan Province. Tidal rice farming performance that would be assessed include production capabilities, the level of technical efficiency of farming using stochastic frontier production function approach (stochastic frontier production) as well as internal factors and external are believed to affect the level of efficiency of tidal rice farming is being investigated.

The production function used is the Cobb-Douglas stochastic frontier production function. The selection of the Cobb-Douglas production function as an approach based on consideration for the measurement of technical efficiency by using the approach of the input side and the output side of an integrated, requires a homogeneous production function. The production function that meet the criteria are homogenous Cobb-Douglas production function, because the prevailing assumption of Cobb-Douglas is constant return to scale. In addition, the shape of the production function is to reduce the heteroscedasticity occurrence and the form of this function most widely used in research, in particular, research fields of agriculture, as well as the calculation is simple and can be done with a computer program that has been provided.

Stochastic Frontier Production Function Model. Specifications model used to estimate parameters of estimation of Cobb Douglas production function approach is Stochastic Frontier Production. Factors thought to directly affect the production are the factors of production used by farmers, covering a total area of land, seeds, inorganic fertilizers $(\mathrm{N}, \mathrm{P}$, $\mathrm{K})$, pesticides and labor.

The analysis was conducted by Frontier 4.1 software. The empirical model of CobbDouglas stochastic frontier production function used in this study were formulated in the following equation:

$$
\ln P D=\beta_{0}+\beta_{1} \ln L L_{i}+\beta_{2} \ln B N_{i}+\beta_{3} \ln P A O_{i}+\beta_{4} \ln P P_{i}+\beta_{5} \ln T K_{i}+\left(V_{i}-U_{i}\right)
$$

Where: $P D=$ Total output (production) $(\mathrm{kg}) ; \mathrm{LL}=$ Area planted (ha); $\mathrm{BN}=$ Number of seeds $(\mathrm{kg}) ; \mathrm{PAO}=$ The amount of inorganic fertilizer or NPK $(\mathrm{kg}) ; \mathrm{PP}=$ Total pesticides (It); $\mathrm{TK}=$ Total labor $(\mathrm{HOK}) ; \mathrm{i}=$ Number of respondents; $\mathrm{V}_{\mathrm{i}}-\mathrm{U}_{\mathrm{i}}=$ error term (effect of inefficiency in the model); $V_{i}=$ random variables related to external factors (climate, pests / diseases and error modeling) spreading symmetric and normal spread $\left(\mathrm{V}_{\mathrm{ij}} \sim \mathrm{N}\left(0, \sigma v^{2}\right) ; \mathrm{U}_{\mathrm{i}}=\right.$ non-negative random variables and assumed to affect the level of technical and inefficiencies associated with internal factors and distribution are half normal $\left(\mathrm{u}_{\mathrm{it}} \sim \mid N\left(0, \sigma v^{2} \mid\right)\right.$. 
The expected value of the coefficient is: $\beta_{1}, \beta_{2}, \beta_{3}, \beta_{4}, \beta_{5}>0$.

Technical Efficiency Measurement. Measurement of technical efficiency of production of tidal rice farming for farmers-i estimated by the following formula (Coelli, et al, 2005):

$$
T E_{i}=\frac{y_{i}}{y_{i}^{*}}=\frac{\exp \left(x_{i} \beta+v_{i}-u_{i}\right)}{\exp \left(x_{i} \beta+v_{i}\right)}=\exp \left(-u_{i}\right)
$$

Where: $y_{i}$ is the actual production of observations, $\mathrm{yi}^{*}$ is the estimated production frontier derived from stochastic frontier production function. Technical efficiency to a farmer ranges between 0 and 1 . The value of the technical efficiency is inversely related to technical inefficiency effects and is only used for functions that have a certain number of outputs and inputs (cross section data). Testing parameters of stochastic frontier and technical inefficiency effects done in two stages. The first stage is a $\beta_{j}$ parameter estimation using Ordinary Least Squares (OLS), The second stage is the estimation of all the parameters $\beta_{0}, \beta_{j}$ and variations in $u_{i}$ and $v_{i}$ by using Maximum Likelihood (MLE) at a confidence level of 5 percent and 10 percent.

Hypothesis testing is done by using the likelihood ratio statistic (likelihood ratio test) are generalized to decide to accept or reject the hypothesis. The value of the test statistic is calculated using the formula:

$$
L R=-2\left\{\ln \left[\frac{L\left(H_{0}\right)}{L\left(H_{1}\right)}\right]\right\}=-2\left\{\operatorname{Ln}\left[L\left(H_{0}\right)\right]-\operatorname{Ln}\left[L\left(H_{i}\right)\right]\right\}
$$

Where: $L\left(\mathrm{H}_{0}\right)$ and $L\left(\mathrm{H}_{1}\right)$ respectively is the value of the likelihood function from the null hypothesis and the alternative hypothesis.

Test criteria:

- LR error one side $>x^{2}$ restraction (Kodde Palm Table), then reject Ho;

- LR error one side $<x^{2}$ restraction (Kodde Palm Table), then accept Ho.

If the hypothesis is accepted, it means that not indicate a technical inefficiency effects, or no deviation in frontier production associated with technical inefficiency, but only related to the stochastic error.

Inefficiency Analysis of Rice Farming. To estimate the inefficiency factor or factors that affect the level of efficiency used a tobit regression model. The use of tobit regression is more appropriate because the value of the dependent variable, that is, efficiency index is limited (censored) between 0 and 100 (Greene 1991; Hossain 1988) in Bravo-Ureta and Pinheiro (1997) and Areerat, et.al. (2012). Model to calculate TE (Technical Efficiency) analyzed separately. Parameter estimation in tobit regression using MLE (Maximum Likelihood Estimator).

The independent variables are supposed to influence the level of technical efficiency in this study uses the same independent variables. Some researchers include Bravo-Ureta and Pinheiro (1997), and Kehinde and Awoyemi (2009) also uses the same independent variables to identify the source of technical inefficiency.

Model estimates of factors that affect the level of efficiency using Tobit models are presented as follows:

$$
T E i=\beta_{0}+\beta_{1} U P+\beta_{2} P F+\beta_{3} P L+\beta_{4} P T+\beta_{5} L L+\beta_{6} A T+\beta_{7} D D+\varepsilon
$$

Where: $\mathrm{TE}=$ level of technical efficiency; UP = Age of Farmers (years); $\mathrm{PF}=$ formal education (years); $\mathrm{PL}=$ Frequency attend the training / counseling in the last year or informal education (times); $\mathrm{PT}=$ rice farming experience (years); $\mathrm{LL}=$ Area planted (ha); $\mathrm{AT}=$ Total number of households (people); $\mathrm{DD}=$ dummy variable for the main job; $1=$ farmer; $0=$ others.

All parameters of efficiency levels estimated by maximum likelihood method (MLE) using Stata program ver. 11. The likelihood ratio test was used to test the estimation of parameters simultaneously, while the test parameters are used: 
Simultaneously test used to test parameters simultaneously.

$$
\begin{gathered}
H_{0}: \beta_{1}=\beta_{2}=\cdots=\beta_{k}=0 \\
\mathrm{H} 1: \text { At least there is one } \beta_{i} \neq 0
\end{gathered}
$$

Statistical test:

$$
x_{\text {calculated }}^{2}=-2 \ln \left(\frac{L_{\text {alternative }}}{L_{\text {full }}}\right)
$$

Where: $L_{\text {alternative }}=$ maximum possible value without loading the independent variables; $\mathrm{L}_{\text {full }}=$ Maximum possible value which contains the free variable.

Testing criteria:

By taking significance level of $\alpha$, then from Table of Distribution Chi-Square with probability $=1-\alpha$ and $d k=k$ obtained $x_{(1-\alpha ; k)}^{2}$ then: Ho rejected if $x_{\text {calculated }}^{2} x_{(1-\alpha ; k)}^{2}$ or if the probability $x^{2}$ calculated $<\alpha$.

Individual test:

This test is performed to examine each individually. $\beta_{j}$

$$
\begin{aligned}
& H_{o}: \beta_{j}=0 \\
& H_{1}: \beta_{j} \neq 0
\end{aligned}
$$

Statistical test:

$$
W=\frac{\hat{\beta}_{j}}{S E(\hat{\beta} j)}
$$

Where: $\hat{\beta} j=$ the estimated coefficient of a certain predictor variable; SE $(\hat{\beta} j)=$ standard error. Testing criteria:

$H_{\circ}$ is rejected at the level of specific $\alpha$ if $W>t$ table or a probability value $<\alpha$.

\section{RESULTS AND DISCUSSION}

Technical Efficiency Analysis. Each farmer has the ability to produce a number of different production. Differences in the amount produced by farmers are not only due to differences in the amount of inputs used, but also could be due to differences in the each farmer managerial skill. The production function estimated using the OLS can only see the average performance of farmers, and not able to see the difference between farmerr managerial capabilities. To find out differences in production quantities are caused by differences in the managerial ability used Maximum Likelihood Estimation (MLE).

Maximum Likelihood Estimation (MLE) can explain the ratio between actual production results of farmers with production potential that should have been achieved by farmers. Comparison of this production will generate exponent value $U_{i}\left(\exp u_{i}\right)$ which is a technical coefficient. The efficiency coefficient value between zero and one. Farmers managerial ability described as technical efficiency levels. There are two steps to determine the value of technical efficiency. The steps are the OLS and MLE.

In OLS estimation only reveals a level of average production. The results of the OLS estimation method will be used as an initial value in the next estimation using MLE method to determine the best production level that can be achieved from the combined use of existing production factors (Coelli et al, 1998). The results of the analysis of frontier production function of rice farming using MLE estimates are presented in Table 1.

Based on the data presented in Table 1 showed the results of estimation of CobbDouglas Stochastic Frontier production function using MLE approach. In the MLE estimates, the variables that affect the rice production is area planted, inorganic fertilizers and pesticides. Input area planted impact on rice production at $99 \%$ significance level. The 
regression coefficient of 0.7921 planting area shows that if the acreage is added by $1 \%$, the production of rice will increase by $0.7921 \%$, in other words if the rice production was about to be increased by $1 \%$ can be done through the addition of the acreage amounted to $1.2625 \%$.

Table 1 - Results Parameter Estimation of Stochastic Frontier Production Function tidal rice farming using OLS and MLE

\begin{tabular}{|c|c|c|c|c|c|c|}
\hline \multirow{2}{*}{ Variables } & \multicolumn{3}{|l|}{ OLS } & \multicolumn{3}{|l|}{ MLE } \\
\hline & Coefficient & Sd. Error & $\mathrm{t}$ & Coefficient & Sd. Error & $\mathrm{T}$ \\
\hline intercept & 6.9523 & 1.0448 & 6.6542 & 6.9527 & 0.9636 & 7.2154 \\
\hline Area planted & 0.7921 & 0.2192 & 3.6144 & 0.7921 & 0.2016 & *** 3.9294 \\
\hline Number of Seeds & 0.0593 & 0.0822 & 0.7216 & 0.0593 & 0.0776 & 0.7641 \\
\hline Number of Inorganic Fertilizer & 0.0736 & 0.0189 & 3.8933 & 0.0736 & 0.0170 & $* * * 4.3300$ \\
\hline Number of Pesticides & -0.0307 & 0.0152 & -2.0254 & -0.0307 & 0.0141 & ** -2.1764 \\
\hline Total manpower & 0.1269 & 0.2034 & 0.6237 & 0.1269 & 0.1878 & 0.6756 \\
\hline $\begin{array}{l}\text { Sigma-squared } \\
\qquad\left(\sigma_{s}^{2}=\sigma^{2}+\sigma_{v}^{2}\right)\end{array}$ & 0.0058 & & & 0.0051 & 0.0011 & $* * * 4.8485$ \\
\hline $\begin{array}{l}\text { Gamma } \\
\qquad\left(\gamma=\frac{\sigma^{2}}{\sigma^{2}+\sigma_{v}^{2}}\right)\end{array}$ & & & & 0.0001 & 0.0334 & 0.0017 \\
\hline Log likelihood & 61.0409 & & & 61.0409 & & \\
\hline
\end{tabular}

Inorganic fertilizer inputs that affect the production of rice at $99 \%$ significance level. The regression coefficient of 0.0736 indicates inorganic fertilizer when the use of inorganic fertilizers added by $1 \%$, the production of rice will increase by $0.0736 \%$, in other words if the rice production was about to be increased by $1 \%$ can be done through the addition of inorganic fertilizer use by $13.5870 \%$.

Input pesticides significantly affect rice production at $95 \%$ significance level. The regression coefficient of -0.0307 pesticides showed that rice production would decrease by $0.0307 \%$ if the use of pesticides increased $1 \%$. This shows that the use of pesticides considered to be redundant with the average use of 1.34 I per ha. Excessive use of pesticides among others, can lead to death of natural enemies to pests, diseases and weeds rice (Kurniawan, AY 2010)

To test the hypothesis of the presence or absence of technical inefficiency effects can be seen through the $\gamma$ grades. $\gamma$ values in Table 2 is 0.0001 and significant at a confidence level of 99.99 percent. Thus there is the technical inefficiency effects that affect the level of production of each farmer resulting in farmers do not produce optimally. Value of 0.0001 indicates that the inability of farmers to achieve maximum production solely due to farmers managerial factor of 0.01 percent, while 99.99 percent are caused by other factors (inputs). Value of $\sigma_{s}^{2}$ (sigma squared) is also an indicator of technical efficiency. Value of $\sigma_{s}^{2}$ is the error term of the regression equation generated from a wide variety of external random $\left(\sigma_{v}^{2}\right)$ and a variety of technical inefficiency $\sigma_{u}^{2} . \sigma_{s}^{2}$ is a total deviation that describes the actual rice production deviation $(\gamma)$ with a potential production that should have been achieved farmer $(\gamma *)$. If the value of $\sigma_{s}^{2}=0$, then there is no difference between the actual production of the farmers with the potential production, so it can be said that technical efficiency is achieved. However, if the value $>0$, then the farm has not been efficient. In Table 2 value is 0.0051 with a confidence level of $99 \%$. This suggests that rice farming in the research area did not meet the technical efficiency. Thus, based on $\gamma$ and $\sigma_{s}^{2}$ values, it could be concluded that the tidal rice farming had not reached the technical efficiency.

The level of technical efficiency of each farmer had very diverse differences. The average technical efficiency in the research area was 0.9996 . This means that the level of technical efficiency in the research area was quite high, because the average level of technical efficiency in the study area near the level expected efficiency that is equal to 1 . The results also showed that the ability of farmers in using minimal input to generate a certain level of output is still necessary improved. Average efficiency level showed that the use of 
physical inputs could still be saved; farmers should save input up to 0.0004 percent. Distribution of technical efficiency is presented in Table 2.

Table 2 - Distribution of technical efficiency levels achieved by rice farmers

\begin{tabular}{|c|c|c|c|}
\hline No. & Technical Efficiency level & Number of Farmers & Percentage (\%) \\
\hline 1. & 0.99957225 to 0.99957458 & 13 & 26.00 \\
\hline 2. & 0.99957459 to 0.99957692 & 30 & 60.00 \\
\hline 3. & From 0.99957693 to 0.99957926 & 7 & 14,00 \\
\hline & Total & 50 & 100.00 \\
\hline & Minimum & 0.99957225 & \\
\hline & Maximum & 0.99957924 & \\
\hline & Average & 0.99957551 & \\
\hline
\end{tabular}

Based on the data presented in Table 2, showed that the highest efficiency value of which is owned by the farmer in the research area is 0.99957924 , while the lowest efficiency value is 0.99957225 . Distribution level of technical efficiency of farming in the study area showed that the highest proportion is in scale 0,99957459 - 0.99957692 amounted to $60.00 \%$, while on a scale of 0.99957693 to 0.99957926 amounted to 14.00 percent. Based on technical efficiency levels of distribution there are 24 farmers (48\%) were still below the average level of efficiency, while the remaining $26(52 \%)$ are above the average level of efficiency.

Analysis of Factors Affecting Technical Inefficiency. TE value on the SFA approach has a variation that capable to be described by its independent variables. There are two variables in parameter values on the SFA model affecting TE. A significant factor affecting the TE is the number of household members at the level of $95 \%$ and the frequency of extension at $90 \%$ confidence level, as shown in Table 3.

Table 3 - Factors Affecting Rice Farming Technical Inefficiency

\begin{tabular}{|c|c|c|c|c|}
\hline \multirow{2}{*}{ Variables } & \multicolumn{4}{|c|}{ SFA } \\
\hline & Coef. & Std. err & $T$ & $P>t$ \\
\hline Intercept & 0.9995729 & 0.000002 & 500000.00 & 0000 \\
\hline Age Farmers & 0.0000000543 & 0.000000122 & $0: 44$ & 0659 \\
\hline Formal education & 0.000000149 & 0.000000102 & $1: 46$ & 0151 \\
\hline Frequency Extension & -0.000000449 & 0.000000235 & -1.91 & ${ }^{*} 0062$ \\
\hline Farming experience & 0.0000000145 & 0.000000119 & $0: 12$ & 0904 \\
\hline Plant Size & 0.000000116 & 0.000000270 & $0: 43$ & 0669 \\
\hline Number of Household Members & -0.000000436 & 0.000000213 & -2.05 & ** 0046 \\
\hline The main job & 0.000000272 & 0.000000648 & $0: 42$ & 0667 \\
\hline Sigma Squared & 0.00000128 & 0.000000130 & & \\
\hline Log Likelihood & \multicolumn{4}{|c|}{594.28546} \\
\hline LR Chi2 (7) & \multicolumn{4}{|c|}{$14: 04$} \\
\hline Prob> chi2 & \multicolumn{4}{|c|}{0.0505} \\
\hline $\begin{array}{l}* * *= \\
* *= \\
* * *=\end{array}$ & \multicolumn{4}{|c|}{$\begin{array}{l}\text { significantly different at the } 90 \text { percent confidence level or table }=1.6794 \\
\text { significantly different at the level of } 95 \text { percent or table }=2.0141 \\
\text { significantly different at the } 99 \text { percent confidence level or table }=2.6896\end{array}$} \\
\hline
\end{tabular}

Number of household members found positive effect on technical inefficiency, which means that the greater the number of family members, the farmers tend to be less efficient technically. This finding was consistent with findings by Kurniawan (2010), which uses a variable dependency ratio, but different from the findings by Mariyah (2008). This suggests that rice farming was not the main livelihood. Farmers were still looking for another job, such as becoming building workers and small traders in order to meet the needs of his family. Consequently farmland were neglected.

Frequency of counseling also found positive effect on technical inefficiency, meaning that more and more often held extension, farmers tend to be less efficient technically. This finding is consistent with findings by Kurniawan and Aurbacher (2015). It is suspected that the more often farmers participated in the extension, the more he lost time to take care of 
their farming land. Especially if rice farming has not been the only livelihood for the farmers and they still do other jobs, so that rice farming land less cared for properly.

\section{CONCLUSION}

Tidal rice production is significantly affected by factors of area planted, inorganic fertilizers and pesticides. The average technical efficiency is already high at 0.9996, approaching 1.0000 as the expected level of efficiency. The inability of farmers in achieving maximum production solely due to farmers managerial factor of 0.01 percent, while 99.99 percent are caused by other factors (inputs). The deciding factor affecting technical inefficiency of rice farming is the number of household members and the frequency of extension.

\section{REFERENCES}

1. Bravo-Ureta, BE and AEPinheiro. 1997. Technical, allocative and Economic Efficiency in Peasant Farming: eviden from the Dominican Republic. The Developing Economics, 35 (3): 48-67.

2. Coelli, TJ. 1996. A Guide to Frontier Version 4.1: A Computer Program for Stochastic Frontier Production and Cost Function. Center for efficiensy and Productivity Analysis. University of New England, Armidale.

3. Coelli, TJ, DSPRao and GEBattese. 1998. An Introduction to Efficiency and Productivity Analysis. Kluwer Academic Publishers, Boston, USA.

4. Coelli, TJ, DSPRao, Donnell, CJ and GEBattese. 2005. An Introduction to Efficiency and Productivity Analysis. Springer Science + Business .Media Inc., 233 Spring Street, New York, NY 10013, USA.

5. South Kalimantan Provincial Agriculture Office TPH. 2016. Annual Report 2015 Department of Agriculture and Horticulture South Kalimantan. Banjarbaru

6. Herman Subagio, M.Noor, WA Yusuf, I.Khairullah. Swamp Land Agricultural Perspective 2015: Support for Food Sovereignty. IAARD Press. Jakarta.

7. Kehinde, AL and TT Awoyemi. 2009. Analysis of Economic Efficiency in Production Sawnwood in Southwest Nigeria. Journal of Hum Ecol, 26 (3): 175183.

8. Kurniawan, AY. 2010. The Factors that Influence Technical Efficiency on Tidal Rice Farming in the Sub-District Anjir Muara, Barito Kuala District, South Kalimantan. EPP Journal vol.7 2, 2010: 40-46.

9. Kurniawan, AY and Joachim Aurbacher. 2015. Economic Efficiency of the Tidal Swampland Farming in Indonesia: Local adn Transmigrant Farming Practice. A Paper presented in Conference on International Research on Food Security, Natural Resource Management and Rural Development. Organized by the Humboldt-Universitat zu Berlin and the Leibniz Center for Agricultural Landscape Research. Berlin, Germany, Sept. 1$18,2015$.

10. Mariyah. 2008. Effect of the Direct Loan Assistance to the Community of the Revenue and Efficiency of Rice Farming in North Paser Penajam East Kalimantan. Master of Science Thesis. Graduate School of Bogor Agricultural University. Bogor, Indonesia. 